University of Wollongong

Research Online

Faculty of Engineering and Information

Faculty of Engineering and Information

Sciences - Papers: Part B

Sciences

2017

\title{
Multifunctional PLLA-ceramic fiber membranes for bone regeneration applications
}

\author{
Daniel Santos \\ Universidade do Porto \\ Dina M. Silva \\ University of Wollongong, dsilva@uow.edu.au \\ Pedro S. Gomes \\ Universidade do Porto \\ Maria H. Fernandes \\ Universidade do Porto \\ Jose Oliveira-Santos \\ Universidade do Porto
}

See next page for additional authors

Follow this and additional works at: https://ro.uow.edu.au/eispapers1

Part of the Engineering Commons, and the Science and Technology Studies Commons

Research Online is the open access institutional repository for the University of Wollongong. For further information contact the UOW Library: research-pubs@uow.edu.au 


\title{
Multifunctional PLLA-ceramic fiber membranes for bone regeneration applications
}

\author{
Abstract \\ A novel method to process electrospun poly(l-lactic acid) (PLLA) membranes incorporating glass \\ reinforced hydroxyapatite granules $(\mathrm{gHA})$ interspacially between the polymeric fibers is reported, thus \\ increasing the surface area for cellular interactions. gHA granules $(\leq 150 \mu \mathrm{m})$ electrospun together with \\ the polymer solution, lead to an average fiber diameter of $550 \pm 150 \mathrm{~nm}$ for pristine PLLA and $440 \pm 170$ \\ $\mathrm{nm}$ for the composite samples. An increase of the overall porosity was observed, from $79 \pm 3 \%$ for the \\ PLLA up to $88 \pm 5 \%$ for the hybrid samples, keeping material's wettability and mechanical properties. \\ Bone-bonding ability showed that both samples induced HA crystal nucleation, but with a distinct pattern \\ of mineral deposition. gHA microcomposite allows a better F-actin cytoskeleton organization during the \\ initial adhesion and spreading, favoring cell-fibers and cell-to-cell interactions and enhanced alkaline \\ phosphatase activity, making them potential candidates for bone healing strategies. \\ Disciplines \\ Engineering | Science and Technology Studies

\section{Publication Details} \\ Santos, D., Silva, D. M., Gomes, P. S., Fernandes, M. H., Santos, J. D. \& Sencadas, V. (2017). Multifunctional \\ PLLA-ceramic fiber membranes for bone regeneration applications. Journal of Colloid and Interface \\ Science, 504 101-110. \\ Authors \\ Daniel Santos, Dina M. Silva, Pedro S. Gomes, Maria H. Fernandes, Jose Oliveira-Santos, and Vitor \\ Sencadas
}


Multifunctional PLLA-ceramic fiber membranes for bone regeneration applications

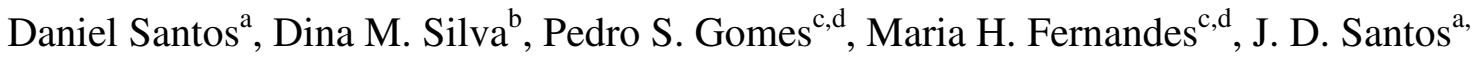

d, Vitor Sencadas ${ }^{\text {e, }}$,*

${ }^{a}$ Faculdade de Engenharia, U. Porto, Rua Dr Roberto Frias, 4200-465 Porto, Portugal.

${ }^{\mathrm{b}}$ Biosckin, Molecular and Cell Therapies, SA. Parque Tecnológico da Maia - Tecmaia, Rua Eng. ${ }^{\circ}$ Frederico Ulrich, 2650, 4470-605 Maia, Portugal.

${ }^{\mathrm{c}}$ Faculdade de Medicina Dentária, U. Porto (FMDUP), 4200-393 Porto, Portugal

${ }^{\mathrm{d}}$ REQUIMTE/LAQV - U. Porto - Porto/Portugal

${ }^{\mathrm{e}}$ School of Mechanical, Materials and Mechatronics Engineering, University of

Wollongong, Wollongong, NSW 2522, Australia.

${ }^{\mathrm{f}}$ ARC Center of Excellence for Electromaterials Science, University of Wollongong, 2522 NSW, Australia

*corresponding author: victors@uow.edu.au 


\begin{abstract}
:
A novel method to process electrospun poly(L-lactic acid) (PLLA) membranes incorporating glass reinforced hydroxyapatite granules (gHA) interspacially between the polymeric fibers is reported, thus increasing the surface area for cellular interactions. gHA granules $(\leq 150 \mu \mathrm{m})$ electrospun together with the polymer solution, lead to an average fiber diameter of $550 \pm 150 \mathrm{~nm}$ for pristine PLLA and $440 \pm 170 \mathrm{~nm}$ for the composite samples. An increase of the overall porosity was observed, from $79 \pm 3 \%$ for the PLLA up to $88 \pm 5 \%$ for the hybrid samples, keeping material`s wettability and mechanical properties. Bone-bonding ability showed that both samples induced HA crystal nucleation, but with a distinct pattern of mineral deposition. gHA microcomposite allows a better F-actin cytoskeleton organization during the initial adhesion and spreading, favoring cell-fibers and cell-to-cell interactions and enhanced alkaline phosphatase activity, making them potential candidates for bone healing strategies.
\end{abstract}

Keywords: Biomaterial; Poly (lactic acid), Glass-reinforced hydroxyapatite, Bone grafts; Electrospun microcomposite fibers, Bone regeneration. 


\section{Introduction}

People suffering from bone defects arising from trauma, tumor or bone diseases is effectively a reality in the present days and every year several million orthopedic procedures are performed [1]. At present, the standard treatments for bone repair involve, in general, autografts, where bone is transplanted from another part of the recipient's body, and allografts, where bone is transplanted from genetically nonidentical members of the same species. These grafting solutions present several limitations, namely donor site scarcity, rejection, disease transmission, need of a separate incision for harvesting and post-operative morbidity $[2,3]$. Therefore, there is a need to explore novel biomaterials in bone tissue engineering, so that the treatment strategy can be as quickly and efficient as possible.

In this context, tissue engineering has an important role to provide functional substitutes for the damaged tissues $[4,5]$. Man-made manufacture substitutes, also known as scaffolds, capable of mimicking the natural tissue environment to successfully meet or perhaps surpass the original mechanical, structural, and functional properties are constantly being developed [4]. The conception of a scaffold with such features is a demanding task, bearing in mind that it should provide a transitional three dimensional support for cell migration, attachment and proliferation, as well as offer mechanical, biological and chemical cues to guide the cells towards tissue restoration [5]. To satisfy those requirements, electrospinning arises as a versatile technique to produce fibrous membranes with same morphology to the ones found in the extracellular matrix (ECM) [4]. Besides, the electrospun fibers with diameters ranging from micro to nanometer scale offer several advantages such as an extremely high surface-to-volume ratio, tunable porosity, malleability to conform to a wide variety of sizes and shapes and the ability to control the fiber composition [6]. Furthermore, scaffolds consisting of 
electrospun fibers can be functionalized for enhanced cellular activities by incorporating bioactive compounds.

The current challenge in bone tissue engineering is to engineer bioartificial bone grafts mimicking the ECM, while allowing effective bone mineralization [1]. Until now, different biomaterials like bioactive ceramics and degradable polymers, have been developed to mimic the mechanical and biological properties required by bone tissue [7]. However, the electroactive properties of these materials, which are important in promoting electrical cues to cells, have been neglected in these advancements. Electroactive polymers are an emergent technology for tissue and biomedical applications. Piezoelectric materials generate transient surface charges by tiny mechanical deformations of the material under mechanical solicitation and do not require additional energy sources or electrodes [8].

PLLA has generated great interest as one of the most promising biodegradable polymers due to its mechanical properties, thermoplastic processability and biodegradability, becoming highly attractive for biological and medical applications [3, 9]. Furthermore, the degradation products of poly(lactides) are nontoxic, which is fundamental for biomedical engineering applications. PLLA is also known for its piezoelectric properties that are in the core of technological applications as sensors [10] and actuators [11]. Moreover, PLLA presents a piezoelectric constant around $10 \mathrm{pC} . \mathrm{N}^{-1}$, similar to the one in human bone, reported to be between 7 - 12 pC. $\mathrm{N}^{-1}[12,13]$. Synthetic glass reinforced hydroxyapatite (gHA) was sintered in the presence of $\mathrm{CaO}$ $\mathrm{P}_{2} \mathrm{O}_{5}$ based glass using a patented process [14]. HA - $\mathrm{Ca}_{10}\left(\mathrm{PO}_{4}\right)_{6}(\mathrm{OH})_{2}$ - is the major mineral constituent of the bone matrix, but its poor mechanical properties and low reabsorption rate by the organism, compromise the recovery of bone normal strength, causing the bone to remain brittle and easily prone to fractures $[15,16]$. gHA particles 
have a highly controlled chemical composition of $\beta$ and $\alpha$ tricalcium phosphates secondary phases known to accelerate biodegradation over HA $[17,18]$. The content of ionic species (such fluoride and sodium, among others) along with its micro and macroporous structure uphold a positive effect in osteoconduction and osteointegration in bone regeneration $[16,19]$.

Bone is a hybrid system of HA and collagen type I fibers, that assembles in a complex and organized porous structure [20]. Electrospun fiber membranes with inorganic HA can mimic the ECM morphology, chemical composition and improves the scaffold mechanical properties [21]. Nevertheless, electrospinning of polymer matrix composites with inorganic fillers are mainly based on the incorporation of HA nanoparticles, which raises issues concerning the immobilization of the ceramic filler on the surface of the fibers. When nanoparticles are used, they often are immobilized in the core of the fiber, and the contact between the active HA filler and the cells is hindered [22]. To overcome this issue and to increase the exposed area of the ceramic to cells, new processing strategies are required.

In this work, we intended to produce hybrid microcomposite electrospun membranes using PLLA as a matrix and gHA micrometer particles as a filler material, and create a topography where the ceramic "islands" appear entrapped in a "sea" of polymeric fibers, increasing the amount of ceramic in direct contact with the cells and the surfaceto-volume ratio of the microcomposite materials. The influence of the gHA in fiber average diameter, wettability and biocompatibility was assessed. The suitability of such composite membrane composition for bone healing and regeneration was explored. 


\section{Experimental:}

gHA synthesis: Ceramic powder was synthetized as per the method described elsewhere $[23,24]$. In this work, using standard milling and sieving techniques, gHA granules with particle size $\leq 150 \mu \mathrm{m}$ were obtained.

Electrospun membrane preparation: Poly(L-lactic acid) (PLLA, Purasorb PL18, $M_{w}=$ $217-225 \mathrm{kDa}$ ) from Corbion (Netherlands) was dissolved in a DMF (Merck):DMC (Sigma-Aldrich) solution $(3: 7 \mathrm{v} / \mathrm{v})$ to achieve a polymer concentration of $10 \mathrm{wt} \%$ of the solution. gHA microcomposite suspensions were prepared by adding the ceramic filler to the DMF:DMC (3:7 v/v) solvent mixture, followed by dispersing in an ultrasound bath (Bandelin, Model Sonorex Super RK106) for $6 \mathrm{~h}$, to promote a good dispersion of the particles. Then, the polymer was added to the mixture and stirred at room temperature until complete dissolution. The concentration of filler related to polymer was $80 \mathrm{wt} \%$.

The neat PLLA and gHA - PLLA solutions were placed in a commercial glass syringe fitted with a metallic needle with $0.5 \mathrm{~mm}$ inner diameter. Electrospinning was conducted at $1.25 \mathrm{kV} . \mathrm{cm}^{-1}$ with a high voltage power supply from Gamma High Voltage. A syringe pump (from KDScientific) was used to feed the polymer solution into the needle tip at $0.5 \mathrm{~mL} \cdot \mathrm{h}^{-1}$. The electrospun fibers were collected in ground collecting plate placed at $20 \mathrm{~cm}$ apart from the needle (random aligned fibers). All experiments were conducted at $21 \pm 2{ }^{\circ} \mathrm{C}$ and a relative humidity of $43 \pm 5 \%$.

Membranes Characterization: Electrospun fiber membranes were coated with a thin gold layer using a sputter coater (Polaron, SC502) and their morphology was analyzed using a scanning electron microscope (NanoSEM FEI Nova200, from FEI) with an accelerating voltage of $10 \mathrm{kV}$. An energy-dispersive X-ray (EDS) was used in 
conjunction with SEM for elemental analysis of the deposited mineral crystals. Fibers average diameter and its distribution was calculated over approximately 50 fibers using the Image J software [25].

Contact angle measurements (sessile drop in dynamic mode) were performed at room temperature in a Data Physics OCA20 device using ultrapure water as test liquid. A sessile drop ( $3 \mu \mathrm{L})$ of ultrapure water (Milli-Q, Millipore) was deposited on the surface of the samples and the contact angle was measured using a DataPhysics OCA 35 goniometer and SCA20 software. For the same sample, contact angles were measured on 8 different spots and the result is expressed as their average and standard deviation. XRD analysis was performed on powder samples of gHA and on PLLA/gHA fiber membranes using a Phillips Analytical X-Ray model PW 1710, employing Cu Ka monochromatic radiation $\left(40 \mathrm{kV}, 30 \mathrm{~mA}, \mathrm{~K}_{\alpha}=1.541838 \AA\right.$ ). Data was collected at room temperature, for $2 \theta$ values ranging from 5 to $70^{\circ}$ in increments of $0.02^{\circ}$ and a counting time of 2 s/step. Thermogravimetric analysis (TGA) was performed in a Q500 apparatus from TAinstruments at heating rate scan of $20^{\circ} \mathrm{C} \cdot \mathrm{min}^{-1}$, under a nitrogen atmosphere. Mechanical properties were performed in a Shimadzu Universal Testing Machine (AGIS with a $10 \mathrm{~N}$ load cell) in tensile mode, at a strain rate of $0.5 \mathrm{~mm} \cdot \mathrm{min}^{-1}$. Rectangular stripes of 10x40 $\mathrm{mm}^{2}$ were measured with a caliper (Mitutoyo) and a thickness of $\sim 250$ $\boldsymbol{\mu}$ m was measured with a DUALSCOPE® MPOR (Fischer). From the stress-strain data, elasticity modulus was calculated in the linear zone, between 0 and $2 \%$ of strain. The values presented were calculated through the average and standard deviation of five individual measurements performed for each sample.

Samples porosity: The porosity of PLLA and gHA-PLLA membranes was measured using the pycnometer method [26]. First, a pycnometer filled with ethanol was weighted 
and labeled as $\mathrm{W}_{1}$. Then, the sample (with a weight of $\mathrm{W}_{\text {sample }}$ ) was immersed in ethanol and, when it was saturated by the ethanol, additional ethanol was added to complete the volume of the pycnometer. The weight of this system was labeled as $\mathrm{W}_{2}$. Finally, the sample saturated with the ethanol was taken out of the pycnometer and the residual weight of the ethanol and the pycnometer was labeled as $W_{3}$. The porosity of each membrane was calculated according to equation 1 . The porosity of each membrane was obtained as the mean value of the porosity determined in three samples.

$$
\varepsilon=\frac{W_{2}-W_{3}-W_{s}}{W_{1}-W_{3}}
$$

Biomimetic mineralization of fiber samples: The simulated body fluid (1.5xSBF) was prepared according to the procedure proposed by Oyane et al. [27] in order to mimic ion blood plasma concentrations. Briefly, $\mathrm{NaCl}, \mathrm{NaHCO}_{3}, \mathrm{Na}_{2} \mathrm{CO}_{3}, \mathrm{KCl}, \mathrm{K}_{2} \mathrm{HPO}_{4}$, $\mathrm{MgCl}_{2} \cdot 6 \mathrm{H}_{2} \mathrm{O}$, HEPES, $\mathrm{CaCl}_{2} \cdot 2 \mathrm{H}_{2} \mathrm{O}$ and $\mathrm{Na}_{2} \mathrm{SO}_{4}$ were accurately weighted and dissolved in ultra-pure water (Milli-Q, Millipore) at $36.5 \pm 0.5^{\circ} \mathrm{C}$, with the help of a magnetic bar. All chemicals were reagent grade from Sigma Aldrich. Final pH was adjusted to 7.40 at $36.5 \pm 0.5^{\circ} \mathrm{C}$ using a $1 \mathrm{M} \mathrm{NaOH}$ solution. $1.5 x \mathrm{SBF}$ freshly prepared solutions were stored in a refrigerator $\left(5-10^{\circ} \mathrm{C}\right)$ in closed plastic containers and used within 30 days after preparation. Solution stability was evaluated by periodic control (7/7 days) of salt precipitation and deposition after $48 \mathrm{~h}$ at $36 \pm 0.5^{\circ} \mathrm{C}$, according to the protocol explained elsewhere [28]. Electrospun PLLA and microcomposite gHA - PLLA membranes were cut into $10 \mathrm{~mm}$ diameter specimens and placed into conical plastic containers. The volume of SBF was calculated according to Kokubo and Takadama method [28] and using the following equation (2): 


$$
V_{s}=\frac{S_{a}}{10}
$$

where $V_{\mathrm{s}}$ is the volume of SBF $(\mathrm{mL})$ and $S_{\mathrm{a}}$ is the apparent surface area of specimen $\left(\mathrm{mm}^{2}\right)$. Immersed samples were kept at $36 \pm 0.5^{\circ} \mathrm{C}$, and for each time point, samples were collected (in triplicates), gently washed with ultra-pure water and dried in a desiccator until SEM and XRD analysis. The SBF solution was renewed every $48 \mathrm{~h}$ to ensure sufficient ion concentrations.

\section{Cytocompatibility assays}

Cell culture: MG 63 osteoblastic-like cells (ATCC number CRL-1427TM, passage 25) were cultured in MEM- $\alpha$ supplemented with fetal bovine serum (FBS, 10\% v/v), $50 \mu \mathrm{g}$ $\mathrm{mL}^{-1}$ ascorbic acid, $100 \mathrm{IU} \mathrm{mL} L^{-1}$ penicillin, $2.5 \mu \mathrm{g} \mathrm{mL}^{-1}$ streptomycin and $2.5 \mu \mathrm{g} \mathrm{mL}^{-1}$ amphotericin $\mathrm{B}$, and maintained at $37{ }^{\circ} \mathrm{C}$ in a $5 \% \mathrm{CO}_{2}$ humidified atmosphere. Cells were seeded in $25 \mathrm{~cm}^{2}$ T-flasks until $70-80 \%$ confluence is reached. Detachment of adherent cells was achieved by a 5 min incubation in $0.05 \%$ trypsin $-0.25 \%$ EDTA solution, at $37^{\circ} \mathrm{C}$. Cell counting was performed using a 1:1 proportion of Trypan Blue and the colorless (viable) cells were counted in a Neubauer haemocytometer chamber. Electrospun PLLA and microcomposite gHA - PLLA membranes were cut out with punch (13-mm in diameter), sterilized under ultraviolet (UV) light for 30 min each side, and pre-incubated with the $\alpha$-MEM for $2 \mathrm{~h}$ at $37^{\circ} \mathrm{C}$ in a humidified atmosphere of $95 \%$ air and $5 \% \mathrm{CO}_{2}$. Specimens were then placed onto a 24-well culture plate, being held at the bottom by individual $7.8 \mathrm{~mm}$ diameter Teflon inserts. Cells were seeded over the fiber mats and on tissue culture polystyrene wells (TCPS controls) at a density of $1.5 \times 10^{4}$ cells/well. Cultures were incubated for periods up to 7 days, and characterized for cell viability, alkaline phosphatase (ALP) activity and observation by SEM and 
confocal laser scanning microscopy (CLSM) for cell adhesion, morphology and pattern of cell growth.

Cell viability/proliferation: Cell viability was estimated by the resazurin assay, a nontoxic alamar blue dye (resazurin) that is reduced by intracellular enzyme activity to resofin, a fluorescent form of alamar blue [29, 30]. After 1, 3 and 7 days in culture, the medium was carefully removed from the wells and fresh media with $50 \mu \mathrm{L}$ of $10 \%(\mathrm{v} / \mathrm{v})$ of resazurin solution was added to each well. Samples were then incubated for $3.5 \mathrm{~h}$ at $37^{\circ} \mathrm{C}$ in humidified atmosphere $\left(95 \%\right.$ air $\left./ 5 \% \mathrm{CO}_{2}\right)$. The fluorescence intensity was measured in a Power Wave XS2 spectrophotometer (Biotek) at 530 and $590 \mathrm{~nm}$ for excitation and emission wavelength, respectively.

ALP Activity and Total Protein Content: ALP synthesis by MG 63 osteoblastic-like cells cultured on the fiber membranes and TCPS controls was determined after 3 and 7 days, using $p$-nitrophenyl phosphate (pNPP) solution as the reaction substrate. For this purpose, cultured membranes were gently washed with PBS and with a lysis solution $(0.1 \%$ Triton $\mathrm{X}-100)$ and then samples were stored at $-20^{\circ} \mathrm{C}$ until ALP and total protein measurements.

Thawed samples were then incubated with pNPP in alkaline buffer for $1 \mathrm{~h}$ at $37^{\circ} \mathrm{C}$. The reaction was stopped with $\mathrm{NaOH}(5 \mathrm{M})$ and the absorbance of the hydrolysis product ( $p$-nitrophenol) was immediately measured at $400 \mathrm{~nm}$ using a plate reader (Power Wave XS2 spectrophotometer, Biotek). ALP activity results were normalized by total protein content, quantified by Lowry's method. 
SEM and CLSM observation: For SEM analysis, samples were fixed in $2.5 \%$ glutaraldehyde for $1 \mathrm{~h}$ at room temperature, rinsed with distilled water and dehydrated through immersion for 30 minutes in a series of successive ethanol:water solutions (55, $70,80,90,95$ and $100 \% \mathrm{v} / \mathrm{v}$ of ethanol). Samples were then dried at room temperature and coated with gold prior to SEM analysis. The average cell area was measured using the Image Pro Plus 4.01 analysis software (Media Cybernetics), on five representative fields of each sample.

For CLSM assessment, samples were fixed in 3.7\% paraformaldehyde. Cell cytoskeleton filamentous actin (F-actin) was visualized by treating cells with Alexa Fluor 488-conjugated phalloidin (1:20 dilution; $1 \mathrm{~h})$ and counterstaining with propidium iodide (1 $\mu \mathrm{g} / \mathrm{mL} ; 10 \mathrm{~min})$, for cell nuclei labelling. Stained samples were mounted in Vectashield ${ }^{\circledR}$ and examined in a Leica SP2 AOBS microscope.

Statistics and Data Analysis: All quantitative data is presented as mean \pm standard deviation. Significant differences in statistical analysis were determined using one-way ANOVA test with Tukey's HSD post hoc analysis. Statistical differences are found when $\mathrm{p}<0.05$.

\section{Results and Discussion}

It was reported that the cells can detect and respond to the mechanical properties of the extracellular environment, by altering cytoskeletal organization, cell-substrate adhesion and other important processes for regulating cell behavior [31]. Figure 1 illustrates the fabrication process of the microcomposite gHA - PLLA electrospun membrane. gHA granules were dispersed in a polymer solution and placed in a glass syringe and electrospun according to the previously described in the experimental section. The 
amount of ceramic present in the polymer solution was chosen by trial and error, and the maximum content of filler possible was added to the electrospun solution. Further, the purpose of using of large particles was to immobilize them on the outside of the polymer fibers. This was done to increasing the contact area between the ceramic filler and the cells, and the overall surface overall surface roughness and the local stiffness of the membrane, due to the presence of a soft polymeric matrix and the hard-ceramic filler, which could resemble the native ECM features.

\section{Microcomposite sample characterization}

Figure 2 shows the morphology of the synthetized ceramic filler, pristine polymer fibers and microcomposite electrospun fiber membranes. The ceramic filler particles presented irregular shape and size $(\leq 150 \mu \mathrm{m})$ due to the milling procedure performed during the material synthesis (figure 2a). It was observed that the PLLA electrospun fibers showed a porous and interconnected network of smooth and defect free fibers (figure $2 b$ ).

Furthermore, when the ceramic filler is added to the polymeric solution and the mixture electrospun, a microcomposite with morphologic features like the PLLA membranes is obtained, containing micro sized gHA granules placed in the free spaces between the polymeric cylindrical fibers, producing a configuration like "islands in the sea" (figure

$2 \mathrm{c}$ and $\mathrm{d}$ ). The purpose of this special configuration is to create a membrane surface with homogeneously distributed ceramic filler, generating a topography with heights and valleys, increasing both surface area and roughness. This mechanically challenging substrate may indeed potentiate cell behavior, since it had been related to the increasing of focal adhesions and cytoskeleton organization, migration and differentiation [31-34]. Additionally, the presence of bioactive gHA granules exposed on the outside of the fiber further increases their exposure to cells during culture, as opposed to when they are 
completely wrapped by the polymer or placed in the core of the fiber, which is often observed when nanoparticles are used as fillers [22, 35]. Interestingly, despite the broad size of gHA particles used in this work, small ceramic particles (less than $\leq 100 \mathrm{~nm}$ ) were also immobilized in the surface of the individual fibers (inset of figure $2 \mathrm{~d}$ ). In addition to increasing the roughness of the fibers compared to the neat PLLA fibers, this feature also provides nanotopographic decoration of individual PLLA fibers (hydrophobic) with hydrophilic ceramic nanoparticles. Both micro- and nano patterning associated with stiffness change are typical features of mechanical environment of native ECM, which ultimately modulates cellular responses [31, 36]. Average fiber diameter was calculated over 50 individual measurements with the help of the image $\mathrm{J}$ software. It was observed that PLLA pristine nanofibers have a mean diameter of $510 \pm 150 \mathrm{~nm}$, while the polymer fibers in the microcomposite membranes have an average diameter of $440 \pm 170 \mathrm{~nm}$ (table 1). This decrease in the average fiber diameter is probably due to the charge distribution on the polymer droplets induced by ceramic particles. gHA can be ionized and carry more electrical charges, which will stretch the droplet even further, resulting in a decrease on the final average fiber diameter.

Membrane wettability is an efficient and simple method to evaluate surface properties on polymer fiber surface. Pristine PLLA and microcomposite electrospun membranes present a water contact angle (WCA) around $132 \pm 3^{\circ}$, which suggests a strong hydrophobic behavior for all prepared samples, and the incorporation of the ceramic filler does not change the membrane surface properties (Table 1). The area of the water droplet in contact with the membrane is bigger than the individual gHA microparticles and the WCA is a result of the wettability of the polymer and ceramic all together, and 
due to the high surface area of the polymer fibers, probably their contribution dominates the WCA for the microcomposite samples.

Membranes average porosity was assessed by gravimetric method and applying equation 1 . The average porosity calculated for the pristine PLLA membranes was around $79 \pm 3 \%$, while an increase of the overall porosity up to $88 \pm 5 \%$ was observed for the microcomposite samples (Table 1). This is probably related to the incorporation of micro sized ceramic fillers that disturb packing of the polymer fibers, creating a less dense fiber membrane when compared with pristine PLLA one. In figure $2 \mathrm{~d}$, one can observe that around the gHA microparticles the pore size is bigger between fibers, when compared to the pristine PLLA membrane.

Figure 3 shows the XRD patterns of the synthetized gHA microparticles and the microcomposite polymer matrix membranes. The ceramic filler was composed by hydroxyapatite, and $\beta$ and $\alpha$-tricalcium phosphate (TCP) secondary phases (figure 3 ). XRD pattern of the microcomposite membranes presents only the main diffraction peaks characteristic of the ceramic filler, without any evidence of the crystalline diffraction peaks of the polymeric matrix. The XRD results suggest that when the solvent evaporates during the path between the needle tip and the ground collector, PLLA chain reorganization is fast and the polymer chains do not suffer any rearrangements towards an ordered fashion, thus remaining amorphous. Previous works reported that the electrospinning process leads to the amorphous PLLA chains $[35,37]$, which is in accordance with our XRD results.

Thermal gravimetric analysis allowed the study of the thermal stability of the processed membranes and to quantify the amount of the gHA particles that were effectively added to the microcomposite fiber membrane. It was observed that the PLLA polymer does not have adsorbed water, which corroborates the strong hydrophobic behavior obtained 
from the water contact angle (figure 2). Further, the degradation of the polymer matrix occurs in a single step, with the major weight loss process observed in the range of 300 $-400{ }^{\circ} \mathrm{C}$ (figure 4 ). The comparison between the residual weight of the neat PLLA sample and microcomposite one showed that the amount of ceramic present in the fibrous membrane was around $60 \%$ (figure 4).

The representative quasi-static behavior recorded in tensile mode, for the PLLA and gHA - PLLA samples is presented in figure 5. PLLA electrospun samples presented a maximum stress around $2.8 \pm 1.2 \mathrm{MPa}$ and a strain at break of $38 \pm 7 \%$. However, the microcomposite samples, showed a 5-fold decrease of the maximum stress down to 0.57 $\pm 0.2 \mathrm{MPa}$ and an increase of the strain at break up to $41 \pm 8 \%$. Moreover, the samples are organized in a non-woven fashion, which suggests that only a small amount of fibers can resist to the applied mechanical load, especially for the microcomposite samples, where the increase of the overall porosity decreases the chain entanglement per unit of mass, lead to a decrease of the maximum stress, but without compromising the material stretchability.

\section{Biomimetic mineralization studies}

Biomineralization with simulated body fluids provides a useful in vitro tool when manufacturing biomimetic materials for bone injury repair, as it can provide evidence on material's ability to mimic native topography and chemical composition of bone extracellular matrix, eventually improving scaffold osteointegration [38]. SEM images of mineralized electrospun PLLA and gHA - PLLA microcomposite fibers are depicted in figure 6. 
After being soaked in $1.5 \mathrm{xSBF}$ for 1 week, pristine PLLA membranes exhibited a flat sheet of mineral apatite throughout fibers surface. gHA-PLLA membranes presented more mineralization for the same time point, homogenously dispersed throughout individual fibers and seemed to enwrapped each fiber (insets), even those within the mat. In a time-dependent fashion, mineral deposition increased after 4 weeks for both membranes, presenting however, distinct topography. For pristine PLLA membranes, the development of large spherical minerals covering all the surface was observed, contrasting with the sheet-like morphology observed at week 1. By opposition gHAPLLA microcomposites were represented by smaller and thicker spherulites wrapping the individual fibers (figure $6 \mathrm{c}$ and $6 \mathrm{~d}$ ). In the composite membranes, at the breaking points of the individual fibers, it was possible to observe the single polymeric fibers filling the core of a mineral cylinder and the overall thickness could reach up to 20 microns in diameter. It was confirmed that the biomineralization process in the microcomposite occurs not only on the surface, as it was observed for the pristine PLLA membranes, but also throughout the bulk of the membranes; this effect could be explained by the cumulative effect of an increase in porosity of the microcomposite, which allows a highly efficient ion transport into the inner pores [39] and the transiently supersaturation of $\mathrm{Ca}^{2+}$ and $\mathrm{PO}_{4}{ }^{3-}$, due to gHA dissolution and that may provide nucleation points for HA growth [40].

The nature of the mineral phase was studied by energy dispersive spectroscopy (EDS), performed on the individual fibers, where the spectra showed the presence of $\mathrm{Ca}$ (calcium), $\mathrm{P}$ (phosphorus), and $\mathrm{O}$ (oxygen) as major elements (figure 7a). By using the intensity of the carbon element as a reference, the intensities from phosphorous and calcium seemed to increase with the increasing of the incubation time in the SBF solution. The Ca:P ratio (table 2) obtained for the samples was smaller when compared 
to the stoichiometric HA (Ca:P = 1.67), which suggests the formation of Ca-deficient hydroxyapatite [41]. These results indicate that both PLLA and gHA- PLLA microcomposite membranes promote apatite formation on their surfaces, the main feature to improve osteoinductive properties and osteointegration [28, 42].

The XRD spectra obtained for the pristine and microcomposite samples incubated during different times showed the presence of HA with a broad peak at $2 \theta=32^{\circ}$ and small ones at $2 \theta=26^{\circ}, 28^{\circ}$ and $47^{\circ}$ (figure $7 \mathrm{~b}$ ).

Cytocompatibility studies

Cell viability/proliferation was estimated by the resazurin assay for up to 7 days exposure using an osteoblastic cell line MG-63 and it is reported in figure 8a. Cell density increased gradually with time in culture, as seen by the results observed at days 1, 3 and 7. Values were similar in the three surfaces, i.e. no significant differences were observed between membranes or with controls $(p>0.05)$.

The potential of the developed microcomposite membranes for orthopedic tissue engineering was performed by monitoring the ALP activity, which is an important molecule in hard tissue formation and a hallmark of osteogenesis [43, 44]. ALP activity of MG-63 cells cultured on PLLA and gHA-PLLA fiber membranes, after 3 and 7 days, is shown in figure $8 \mathrm{~b}$. A statistically significant increase $(\mathrm{p}<0.05)$ was found after 7 days for gHA-PLLA membranes when compared to PLLA ones. ALP, a membrane bound enzyme, is synthesized during the early matrix formation and maturation period, and is essential in the onset of mineral deposition. Mineralization initiates in small vesicles that are formed from the cytoplasmic membrane of the osteoblast by a budding process. The membrane vesicles have a high activity of ALP that hydrolyses organic phosphate compounds, providing appropriate concentrations of phosphate ions that concentrate near the membrane. The vesicles also contain proteins and phospholipids 
with calcium-binding ability, allowing the localized accumulation of calcium and phosphate ions. Once the levels of these ions overcome the point of solubility, deposition of calcium phosphate occurs within the vesicles. Upon filling the vesicles, inorganic crystals contact with the extra-vesicular space which, in normal conditions, is rich in calcium and phosphate ions [45-47]. During the extravesicular mineralization, crystals of hydroxyapatite fill the inter-collagen fibrils spaces of the osteoid and, upon the formation of stable mineral "critical nucleus", crystal growth becomes a faster physic-chemical driven process $[43,45,48]$. Due to its role in the osteoblast-mediated mineral deposition, ALP is a widely used biochemical marker of osteoblast differentiation. Back to the present work, the higher ALP activity observed in the gHAPLLA fiber membrane and the expected increased availability of calcium and phosphate ions in the fibrillar matrix due to the presence of the ceramic filler would suggest the possibility of a faster and more efficient matrix mineralization in the microcomposite membrane compared to the PLLA membrane.

Membranes seeded with osteoblastic cells were stained for the F-actin cytoskeleton and nucleus and observed after $24 \mathrm{~h}$ by CLSM (figure 9). The F-actin cytoskeleton is composed of linear actin polymer microfilaments and is an important structure for a wide range of cellular functions. It provides structural stability having an essential role in the establishment of the cell shape and intercellular junctions. F-actin cytoskeleton is highly dynamic to cope with cellular internal needs and response to the surrounding environment, thus being essential in functions such as cell division, intracellular transport, signaling pathways and gene expression, as well as in cell motility and mechano-transduction mechanisms [49-51]. As such, assessment of the re-organization of the F-actin cytoskeleton during the cell adhesion and spreading to new substrates is an early indicator of the subsequent cell behavior. Images on figure $9(\mathrm{a}, \mathrm{c})$ show that 
cells were randomly distributed on both membranes and presented a round-elongated morphology. On the PLLA membrane, cells showed a poor defined F-actin cytoskeleton, with a diffuse globular appearance and little evidence of a filamentous organization on high magnification images (figure 9b); also, some cells presented a nucleus with compacted chromatin and cytoplasm with dense F-actin (figure 9b, bottom). Figure 9c shows that on the gHA-PLLA membranes, cells exhibited betterdefined shape and cytoskeleton organization and well-evident nucleus; additionally, Factin staining was more intense in the cell limits, which is expected as this structure is highly concentrated beneath the plasma membrane. The high magnification images (Figure 9d) show evidence of filamentous actin organization with the actin stress fibers stretching towards the cell ends. These observations suggest a better substrate adaptation on the gHA - PLLA membranes compared to the PLLA membranes, which might be predictive of an improved cell response.

SEM observation also shows that both membranes enabled cellular adhesion and spreading on their surfaces (figure 10) displaying a typical flat phenotype [29] with extended cytoplasm, appearing to interact and associate with surrounding fibers. Comparatively, at day 1, an increased cell spreading was verified on gHA-PLLA membranes with cells adopting a more polygonal morphology and a significant higher cell surface area, whether those grown on PLLA membranes presented a more fusiform structure. In addition, cells with more lamellopodia connecting to the fiber structure of the membrane were clearly identified on gHA-PLLA (Figure 10, inset). Cells proliferated actively and, at day 7, the establishment of intercellular contacts were identified within both formulations, whether increased cell-to-cell contact was observed for gHA-PLLA, further supporting the relevant role of gHA on the adhesion, proliferation and establishment of intercellular contacts. 


\section{Conclusions}

A novel processing method to incorporate gHA microparticles in fiber membranes was developed, which placed a higher number of particles in the porous between the PLLA fibers creating a structure like "islands in a sea", thus increasing both surface area and the roughness. Biomineralization studies showed that gHA - PLLA composites also induced HA crystal nucleation and growth, but with a distinct pattern of mineral deposition. Biological evaluation results indicate that the presence of the gHA microparticles allowed a better F-actin cytoskeleton organization during the initial cell adhesion and spreading, enhanced the cell-fibers and cell-to-cell interactions favoring the formation of a continuous cell layer and, also, increased ALP activity, which make these materials potential candidates for bone healing and repair strategies.

The simplicity of the developed processing method creates a unique combination of stiff microcomposite fiber membranes and makes them potentially suitable for biomedical applications such as bone repair.

\section{Acknowledgments}

V. Sencadas thanks support from the COST Actions MP1206: "Electrospun nano-fibers for bio inspired composite materials and innovative industrial applications". V Sencadas and M. H. Fernandes thanks support from the COST Action MP1301: "New Generation Biomimetic and Customized Implants for Bone Engineering”. Financial support from the European Union (FEDER funds POCI/01/0145/FEDER/007265) and National Funds (FCT/MEC, Fundação para a Ciência e Tecnologia and Ministério da Educação e Ciência) under the Partnership Agreement PT2020 UID/QUI/50006/2013, is also acknowledged. 


\section{References}

[1] Venugopal J, Prabhakaran MP, Zhang Y, Low S, Choon AT, Ramakrishna S. Biomimetic hydroxyapatite-containing composite nanofibrous substrates for bone tissue engineering. Philosophical transactions Series A, Mathematical, physical, and engineering sciences. 2010;368(1917):2065-81.

[2] Navarro M, Michiardi A, Castano O, Planell JA. Biomaterials in orthopaedics. Journal of the Royal Society, Interface / the Royal Society. 2008;5(27):1137-58.

[3] Prabhakaran MP, Venugopal J, Ramakrishna S. Electrospun nanostructured scaffolds for bone tissue engineering. Acta biomaterialia. 2009;5(8):2884-93.

[4] Lyu S, Huang C, Yang H, Zhang X. Electrospun fibers as a scaffolding platform for bone tissue repair. Journal of orthopaedic research : official publication of the Orthopaedic Research Society. 2013;31(9):1382-9.

[5] Wang X, Ding B, Li B. Biomimetic electrospun nanofibrous structures for tissue engineering. Materials today. 2013;16(6):229-41.

[6] Liu H, Ding X, Zhou G, Li P, Wei X, Fan Y. Electrospinning of Nanofibers for Tissue Engineering Applications. Journal of Nanomaterials. 2013;2013:1-11.

[7] Wang M. Developing bioactive composite materials for tissue replacement. Biomaterials. 2003;24(13):2133-51.

[8] Ribeiro C, Sencadas V, Correia DM, Lanceros-Méndez S. Piezoelectric polymers as biomaterials for tissue engineering applications. Colloids and Surfaces B: Biointerfaces. 2015;136:46-55.

[9] Gupta B, Revagade N, Hilborn J. Poly(lactic acid) fiber: An overview. Progress in Polymer Science. 2007;32(4):455-82. 
[10] Masamichi A, Hideki K, Keisuke K, Yoshiro T. Film Sensor Device Fabricated by a Piezoelectric Poly(L-lactic acid) Film. Japanese Journal of Applied Physics. 2012;51(9S1):09LD14.

[11] Tetsuo Y, Kenji I, Takaaki N, Ryouta U, Takuya K, Masataka I, et al. Piezoelectric Motion of Multilayer Film with Alternate Rows of Optical Isomers of Chiral Polymer Film. Japanese Journal of Applied Physics. 2011;50(9S2):09ND13.

[12] Halperin C, Mutchnik S, Agronin A, Molotskii M, Urenski P, Salai M, et al. Piezoelectric Effect in Human Bones Studied in Nanometer Scale. Nano Letters. 2004;4(7):1253-6.

[13] Fukada E. History and recent progress in piezoelectric polymers. Ultrasonics, Ferroelectrics, and Frequency Control, IEEE Transactions on. 2000;47(6):1277-90.

[14] Knowles JC, Hastings GW, Santos JD. Sintered hydroxyapatite compositions and method for the preparation thereof. Google Patents; 2000.

[15] Kim HW, Lee HH, Knowles JC. Electrospinning biomedical nanocomposite fibers of hydroxyapatite/poly(lactic acid) for bone regeneration. Journal of biomedical materials research Part A. 2006;79(3):643-9.

[16] Atayde LM, Cortez PP, Afonso A, Santos M, Mauricio AC, Santos JD. Morphology effect of bioglass-reinforced hydroxyapatite (Bonelike ) on osteoregeneration. Journal of biomedical materials research Part B, Applied biomaterials. 2014.

[17] Queiroz AC, Santos JD, Monteiro FJ, Prado da Silva MH. Dissolution studies of hydroxyapatite and glass-reinforced hydroxyapatite ceramics. Materials Characterization. 2003;50(2-3):197-202. 
[18] Klein CPAT, Wolke JGC, de Blieck-Hogervorst JMA, De Groot K. Features of calcium phosphate plasma-sprayed coatings: An in vitro study. Journal of Biomedical Materials Research. 1994;28(8):961-7.

[19] Oliveira JM, Miyazaki T, Lopes MA, Ohtsuki C, Santos JD. Bonelike®/PLGA hybrid materials for bone regeneration: Preparation route and physicochemical characterisation. J Mater Sci: Mater Med. 2005;16(3):253-9.

[20] Rogers KD, Daniels P. An X-ray diffraction study of the effects of heat treatment on bone mineral microstructure. Biomaterials. 2002;23(12):2577-85.

[21] Neuendorf RE, Saiz E, Tomsia AP, Ritchie RO. Adhesion between biodegradable polymers and hydroxyapatite: Relevance to synthetic bone-like materials and tissue engineering scaffolds. Acta biomaterialia. 2008;4(5):1288-96.

[22] Peng F, Yu X, Wei M. In vitro cell performance on hydroxyapatite particles/poly(llactic acid) nanofibrous scaffolds with an excellent particle along nanofiber orientation. Acta biomaterialia. 2011;7(6):2585-92.

[23] Santos JD, Knowles JC, Reis RL, Monteiro FJ, Hastings GW. Microstructural characterization of glass-reinforced hydroxyapatite composites. Biomaterials. 1994;15(1):5-10.

[24] Lopes MA, Knowles JC, Santos JD. Structural insights of glass-reinforced hydroxyapatite composites by Rietveld refinement. Biomaterials. 2000;21(18):1905-10. [25] Schneider CA, Rasband WS, Eliceiri KW. NIH Image to ImageJ: 25 years of image analysis. Nat Meth. 2012;9(7):671-5.

[26] Cossich E, Bergamasco R, Pessoa de Amorim MT, Martins PM, Marques J, Tavares CJ, et al. Development of electrospun photocatalytic TiO2-polyamide-12 nanocomposites. Materials Chemistry and Physics. 2015;164:91-7. 
[27] Oyane A, Onuma K, Ito A, Kim H-M, Kokubo T, Nakamura T. Formation and growth of clusters in conventional and new kinds of simulated body fluids. Journal of Biomedical Materials Research Part A. 2003;64A(2):339-48.

[28] Kokubo T, Takadama H. How useful is SBF in predicting in vivo bone bioactivity? Biomaterials. 2006;27(15):2907-15.

[29] Laranjeira MS, Fernandes MH, Monteiro FJ. Innovative macroporous granules of nanostructured-hydroxyapatite agglomerates: Bioactivity and osteoblast-like cell behaviour. Journal of Biomedical Materials Research Part A. 2010;95A(3):891-900.

[30] O'Brien J, Wilson I, Orton T, Pognan F. Investigation of the Alamar Blue (resazurin) fluorescent dye for the assessment of mammalian cell cytotoxicity. European Journal of Biochemistry. 2000;267(17):5421-6.

[31] Mason BN, Califano JP, Reinhart-King CA. Matrix Stiffness: A Regulator of Cellular Behavior and Tissue Formation. In: Bhatia SK, editor. Engineering Biomaterials for Regenerative Medicine: Novel Technologies for Clinical Applications. New York, NY: Springer New York; 2012. p. 19-37.

[32] Ghibaudo M, Saez A, Trichet L, Xayaphoummine A, Browaeys J, Silberzan P, et al. Traction forces and rigidity sensing regulate cell functions. Soft Matter. 2008;4(9):1836-43.

[33] Yeung T, Georges PC, Flanagan LA, Marg B, Ortiz M, Funaki M, et al. Effects of substrate stiffness on cell morphology, cytoskeletal structure, and adhesion. Cell Motility and the Cytoskeleton. 2005;60(1):24-34.

[34] Wozniak MA, Modzelewska K, Kwong L, Keely PJ. Focal adhesion regulation of cell behavior. Biochimica et Biophysica Acta (BBA) - Molecular Cell Research. 2004;1692(2-3):103-19. 
[35] Siqueira L, Passador FR, Costa MM, Lobo AO, Sousa E. Influence of the addition of $\beta$-TCP on the morphology, thermal properties and cell viability of poly (lactic acid) fibers obtained by electrospinning. Materials Science and Engineering: C. 2015;52(0):135-43.

[36] Stevens MM, George JH. Exploring and Engineering the Cell Surface Interface. Science. 2005;310(5751):1135-8.

[37] Valente TAM, Silva DM, Gomes PS, Fernandes MH, Santos JD, Sencadas V. Effect of Sterilization Methods on Electrospun Poly(lactic acid) (PLA) Fiber Alignment for Biomedical Applications. ACS Applied Materials \& Interfaces. 2016;8(5):3241-9.

[38] Xie J, Zhong S, Ma B, Shuler FD, Lim CT. Controlled biomineralization of electrospun poly( $\varepsilon$-caprolactone) fibers to enhance their mechanical properties. Acta biomaterialia. 2013;9(3):5698-707.

[39] Chen J, Chu B, Hsiao BS. Mineralization of hydroxyapatite in electrospun nanofibrous poly(L-lactic acid) scaffolds. Journal of Biomedical Materials Research Part A. 2006;79A(2):307-17.

[40] Song Y, Zhang S, Li J, Zhao C, Zhang X. Electrodeposition of Ca-P coatings on biodegradable $\mathrm{Mg}$ alloy: In vitro biomineralization behavior. Acta biomaterialia. 2010;6(5):1736-42.

[41] Cai Q, Xu Q, Feng Q, Cao X, Yang X, Deng X. Biomineralization of electrospun poly(l-lactic acid)/gelatin composite fibrous scaffold by using a supersaturated simulated body fluid with continuous $\mathrm{CO} 2$ bubbling. Applied Surface Science. 2011;257(23):10109-18.

[42] Zhang C, Cao M, Lan J, Wei P, Cai Q, Yang X. Regulating proliferation and differentiation of osteoblasts on poly(l-lactide)/gelatin composite nanofibers via timed 
biomineralization. Journal of Biomedical Materials Research Part A. 2016;104(8):196880.

[43] Lai G-J, Shalumon K, Chen J-P. Response of human mesenchymal stem cells to intrafibrillar nanohydroxyapatite content and extrafibrillar nanohydroxyapatite in biomimetic chitosan/silk fibroin/nanohydroxyapatite nanofibrous membrane scaffolds. International journal of nanomedicine. 2015;10:567.

[44] Rodan G, Rodan S. Expression of the osteoblastic phenotype. Bone and mineral research. 1984;2:244-85.

[45] Golub EE, Boesze-Battaglia K. The role of alkaline phosphatase in mineralization. Current Opinion in Orthopaedics. 2007;18(5):444-8.

[46] Golub EE. Role of Matrix Vesicles in Biomineralization. Biochimica et biophysica acta. 2009;1790(12):1592-8.

[47] Long F. Building strong bones: molecular regulation of the osteoblast lineage. Nat Rev Mol Cell Biol. 2012;13(1):27-38.

[48] Aubin JE, Triffitt JT. Mesenchymal stem cells and osteoblast differentiation. In: Bilezikian JP, Raisz, L.G., Martin, T.J., editor. Principles of bone biology: USA Academy Press; 2002. p. 59-81.

[49] Pollard TD, Cooper JA. Actin, a Central Player in Cell Shape and Movement. Science. 2009;326(5957):1208-12.

[50] Stricker J, Falzone T, Gardel ML. Mechanics of the F-actin cytoskeleton. Journal of Biomechanics. 2010;43(1):9-14.

[51] Blanchoin L, Boujemaa-Paterski R, Sykes C, Plastino J. Actin Dynamics, Architecture, and Mechanics in Cell Motility. Physiological Reviews. 2014;94(1):23563. 
https://doi.org/10.1016/j.jcis.2017.05.032 


\section{Figures}

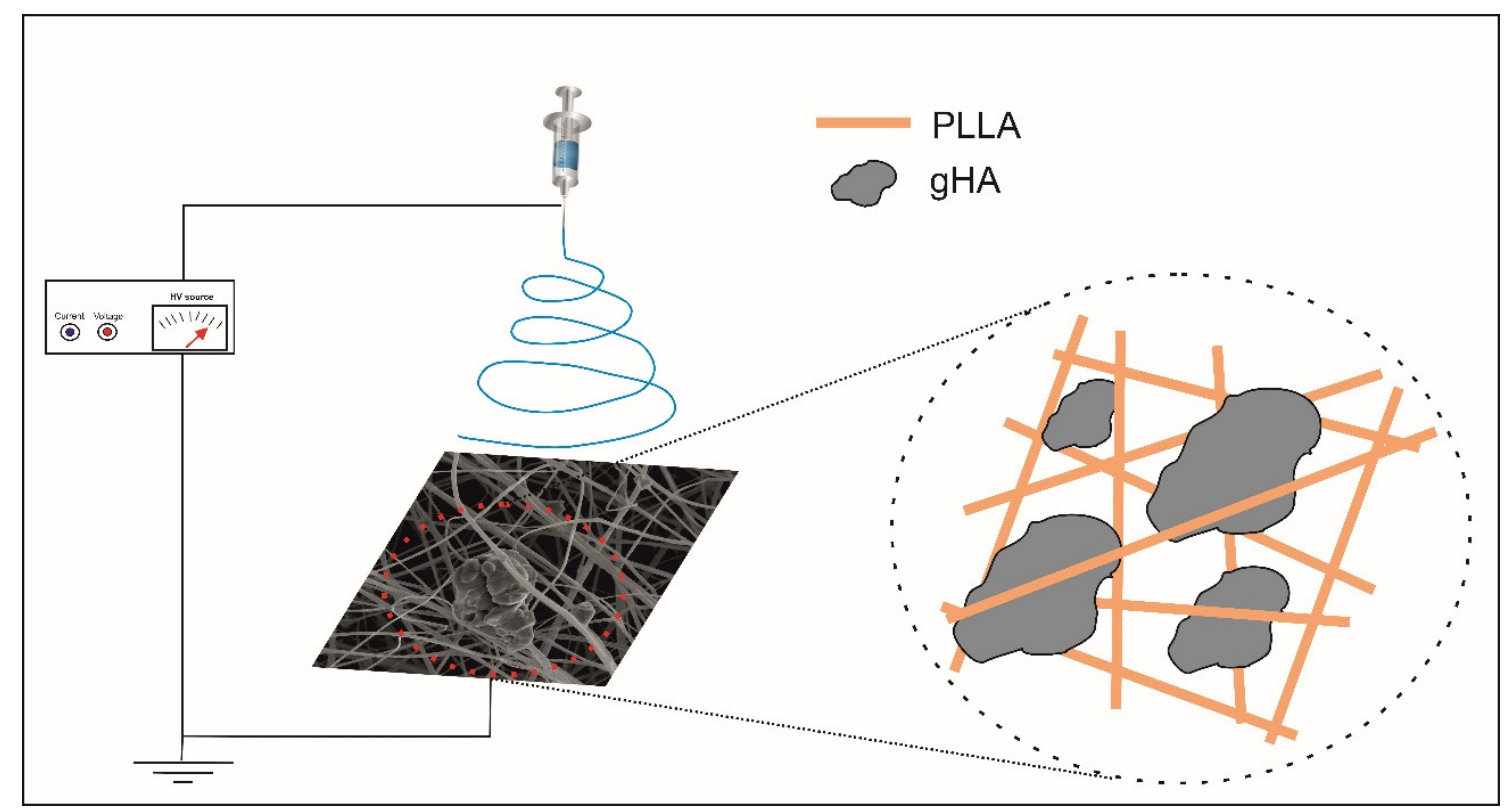

Figure 1. Illustration of the fabrication electrospinning setup used to obtain the gHA -

PLLA membranes. 

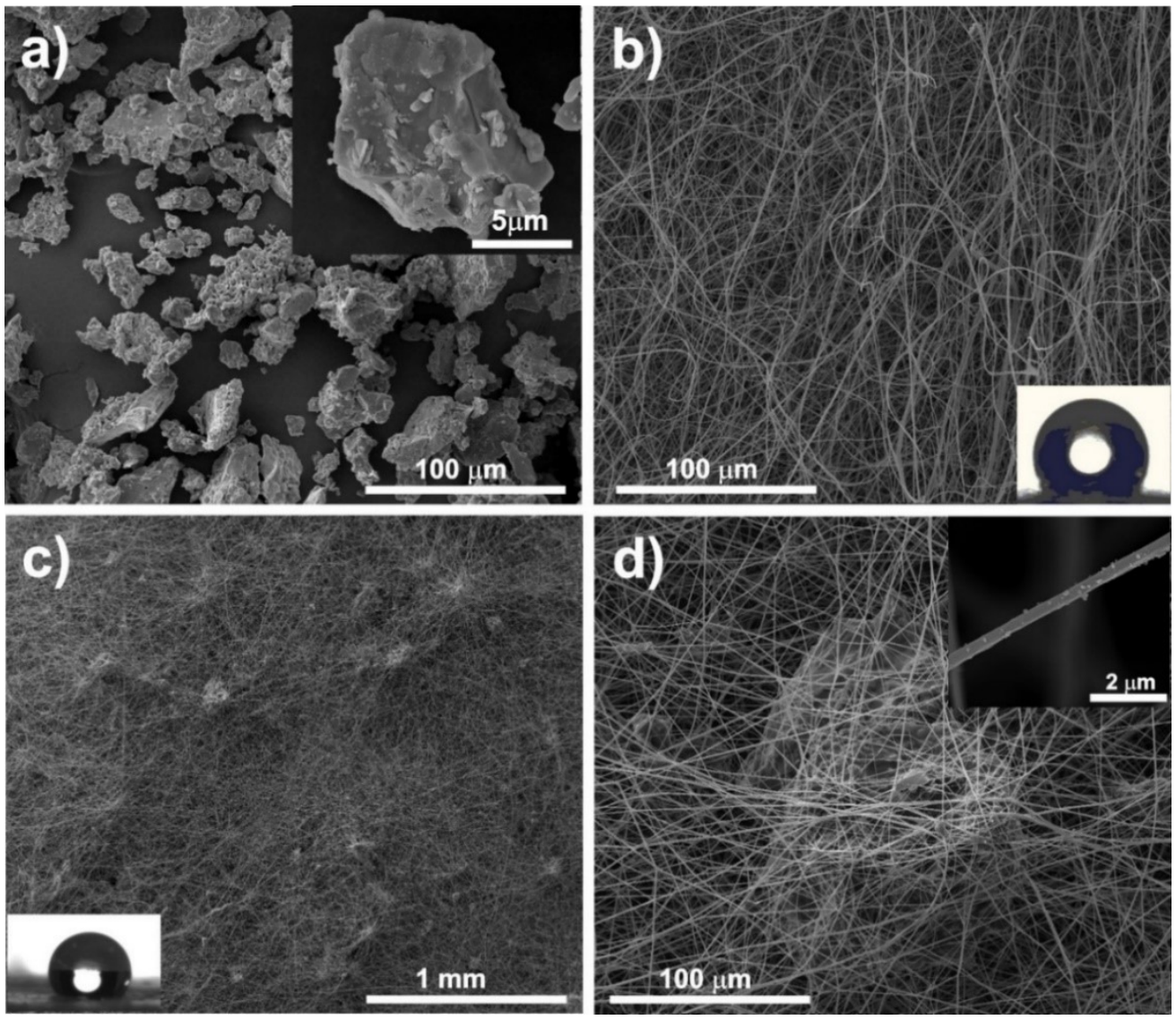

Figure 2. Representative SEM images: a) gHA granules, b) As-spun neat PLLA fibers, c) As-spun gHA - PLLA fibers and d) Detail of a gHA microparticle entrapped in the free space between polymer fibers. Inset: gHA nanoparticles immobilized on the surface of PLLA electrospun fibers. 


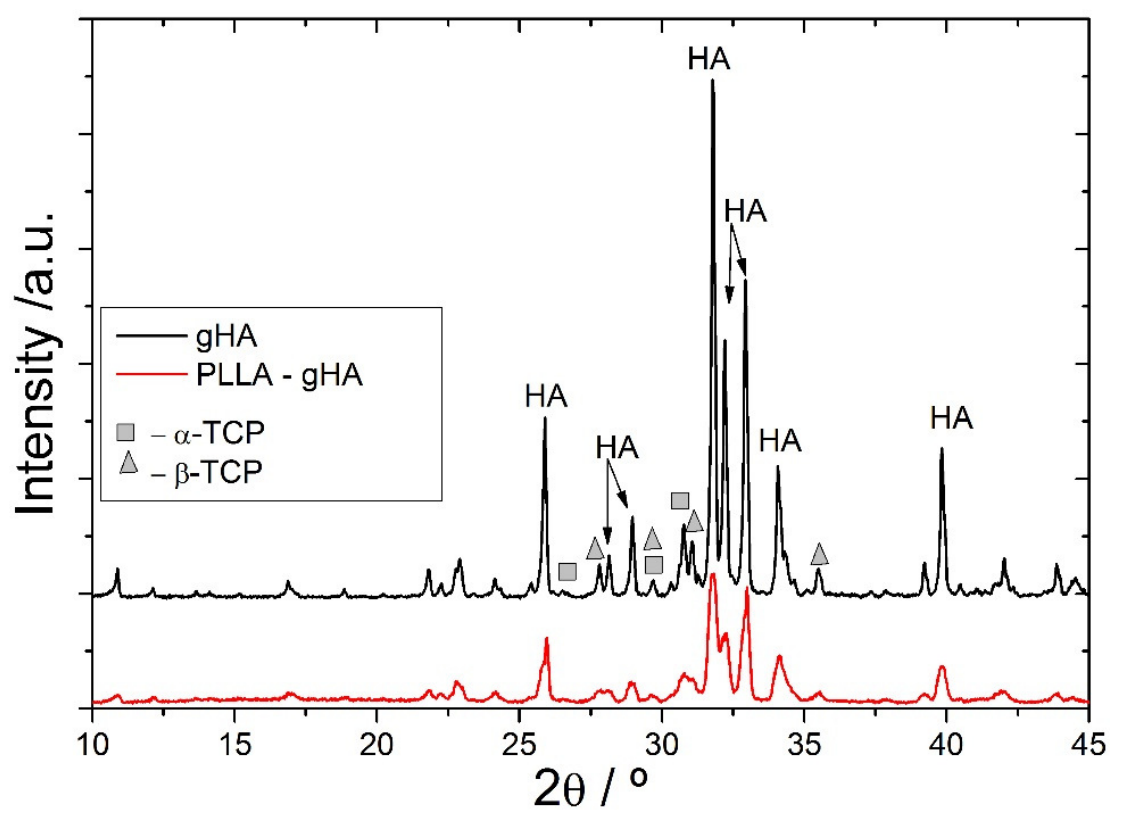

Figure 3. XRD pattern of gHA and PLLA-gHA microcomposite electrospun membranes.
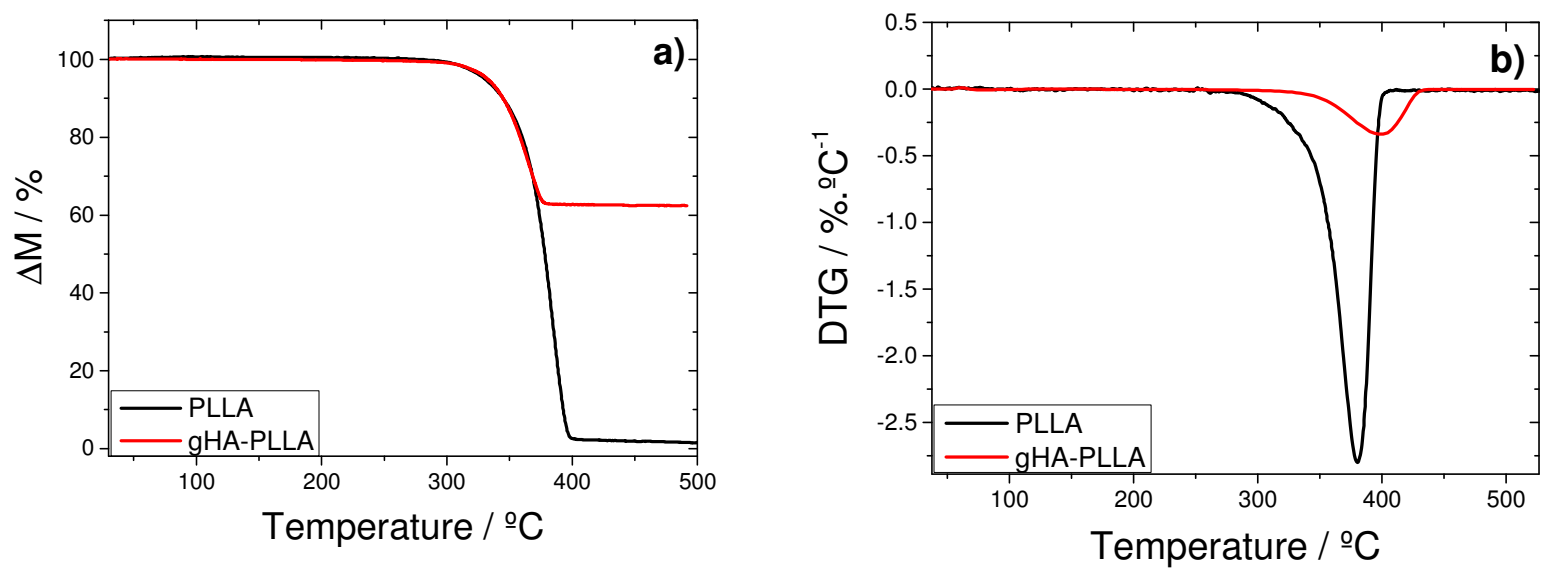

Figure 4. Thermal gravimetric analysis of gHA and PLLA-gHA microcomposite fiber membranes. 


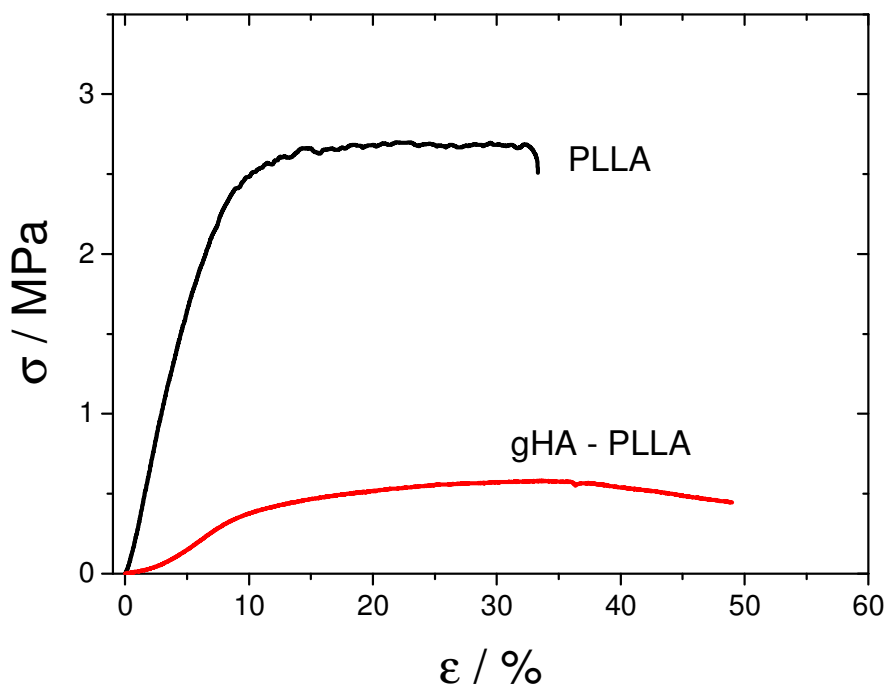

Figure 5. Representative stress-strain data obtained for the neat PLLA and gHA PLLA microcomposite samples. 

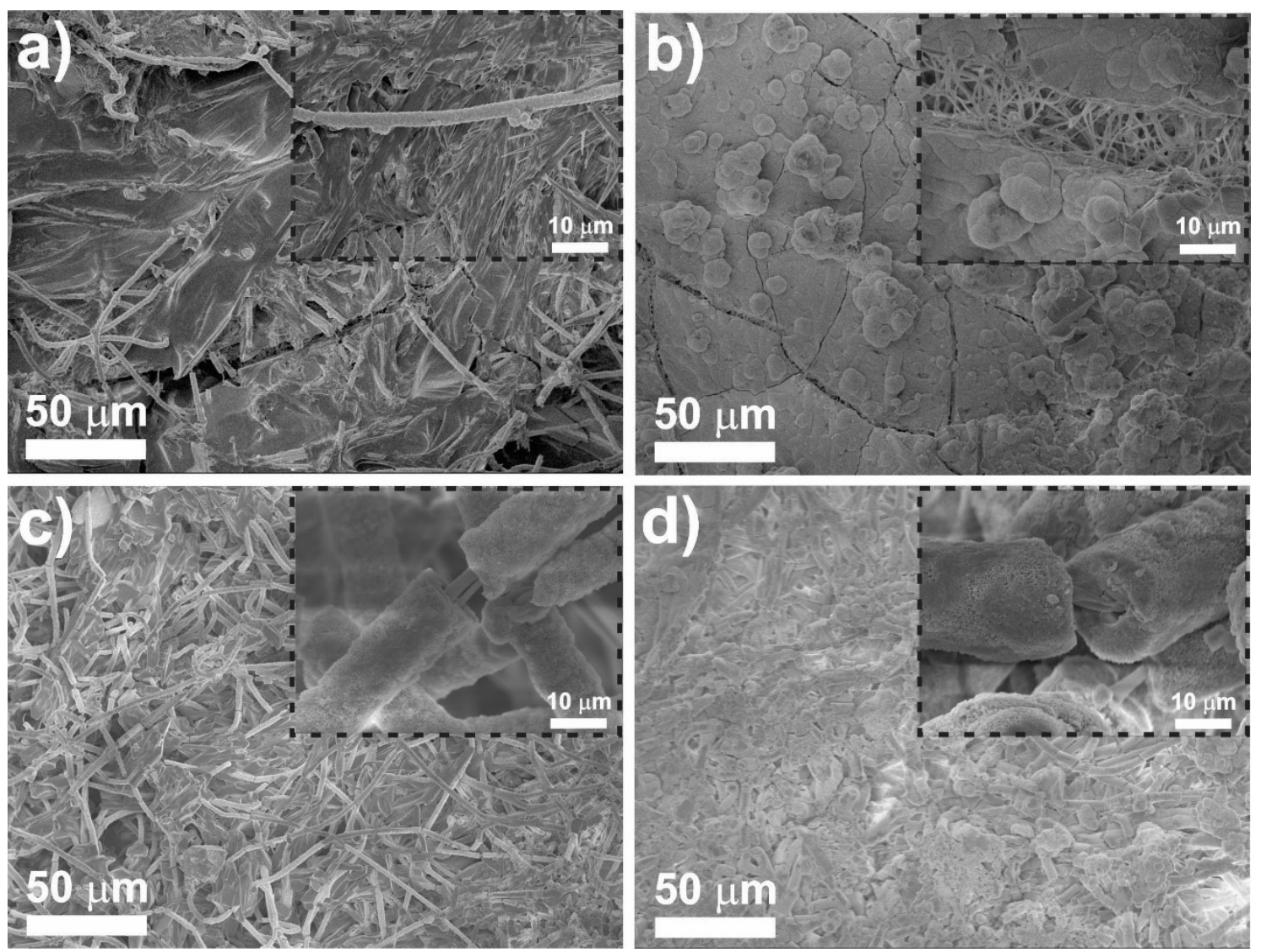

Figure 6. SEM images of electrospun samples submitted to in vitro biomineralization studies: a) PLLA sample after 1 week, b) PLLA sample after 4 weeks, c) gHA-PLLA sample after 1 week and d) gHA-PLLA sample after 4 weeks. Biomineralization studies were performed at $\mathrm{pH}=7.4$ and at $36.5 \pm 0.5^{\circ} \mathrm{C}$ in $1.5 \mathrm{xSBF}$. 

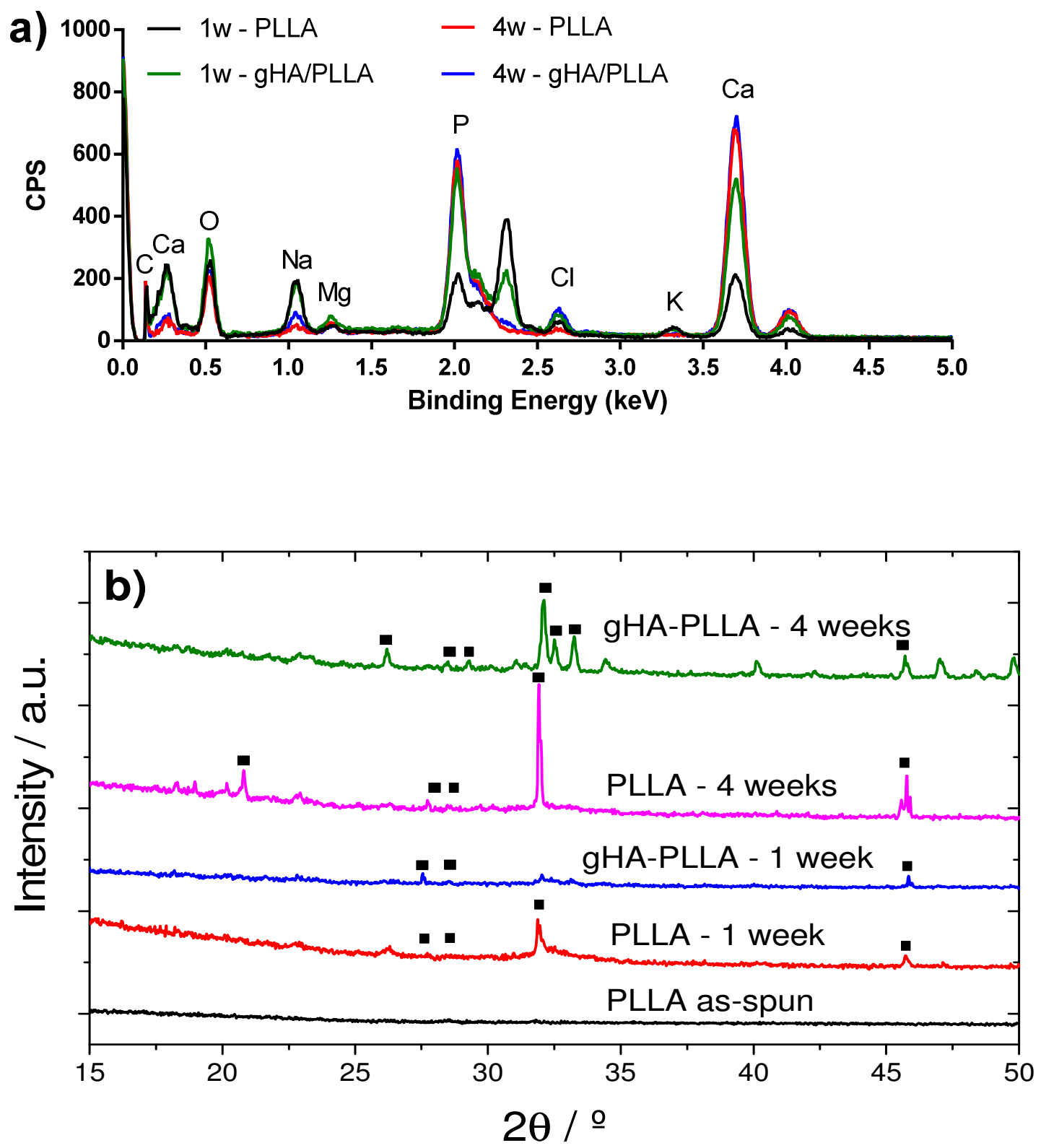

Figure 7. EDS analysis of depositions formed on electrospun fibers after mineralization studies for 1 and 4 weeks in pristine PLLA and gHA - PLLA microcomposite. 

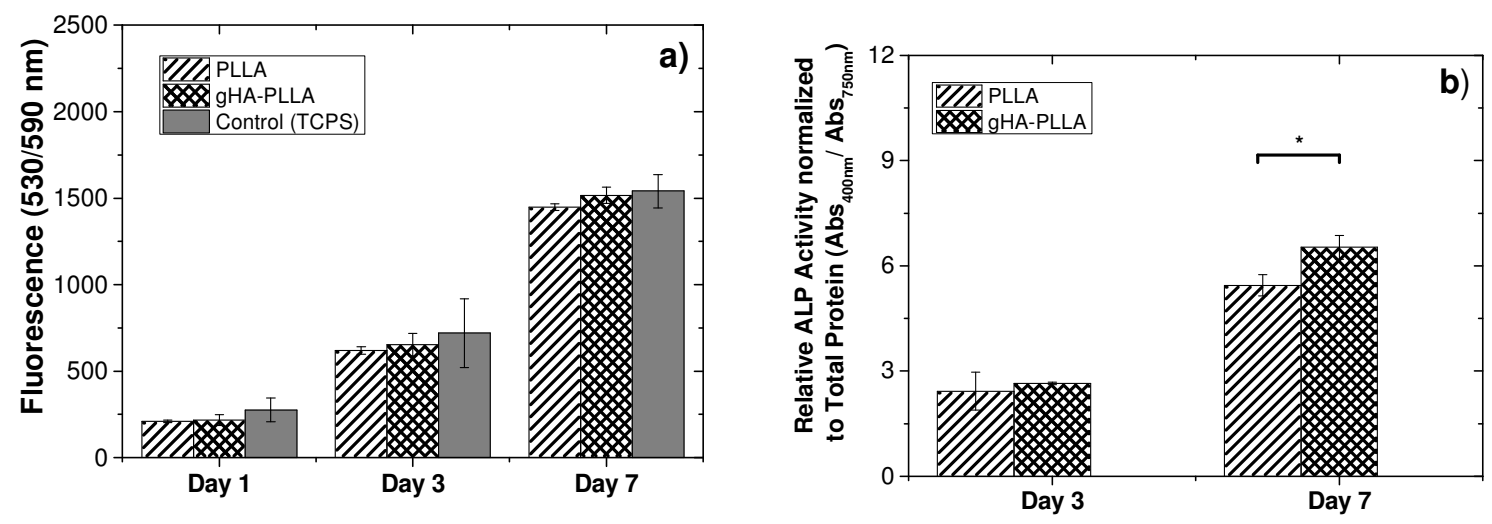

Figure 8. (a) Cell proliferation estimated by resazurin assay and (b) ALP activity of MG-63 cells cultured on PLLA and gHA- PLLA membranes for 1, 3 and 7 days. Controls were performed on TCPS. Data plotted as mean \pm standard. Statistical analysis: ${ }^{*} \mathrm{p}<0.05$.
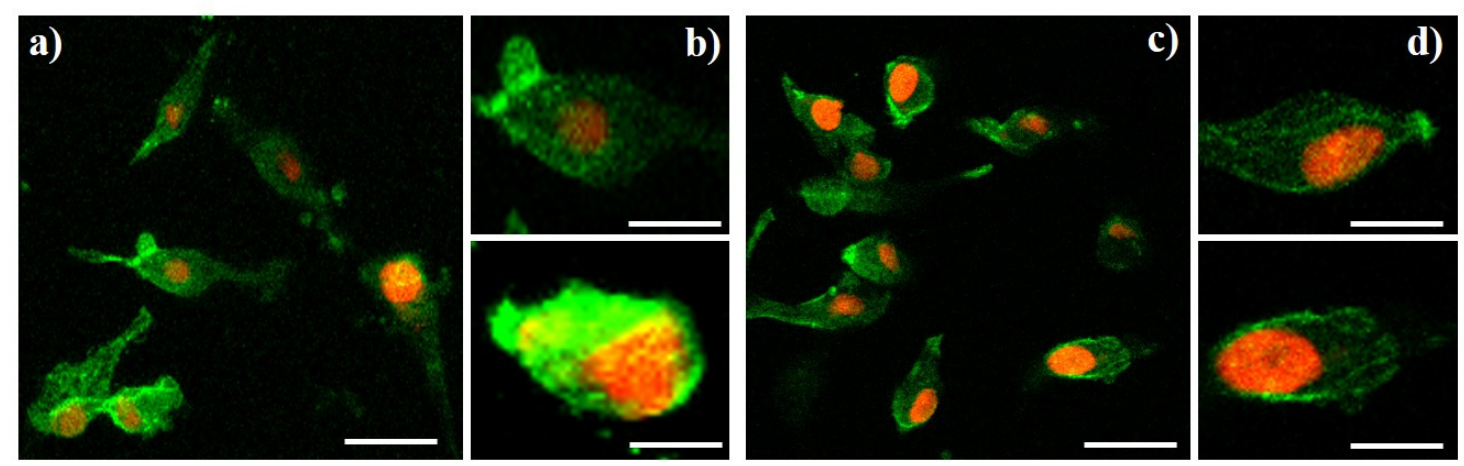

Figure 9. CLSM representative images of MG-63 osteoblastic cells cultured on PLLA (a, b) and gHA- PLLA membranes (c, d) for $24 \mathrm{~h}$. Scale bar: $40 \mu \mathrm{m}$ (a, c) and $20 \mu \mathrm{m}(\mathrm{b}$, d). 

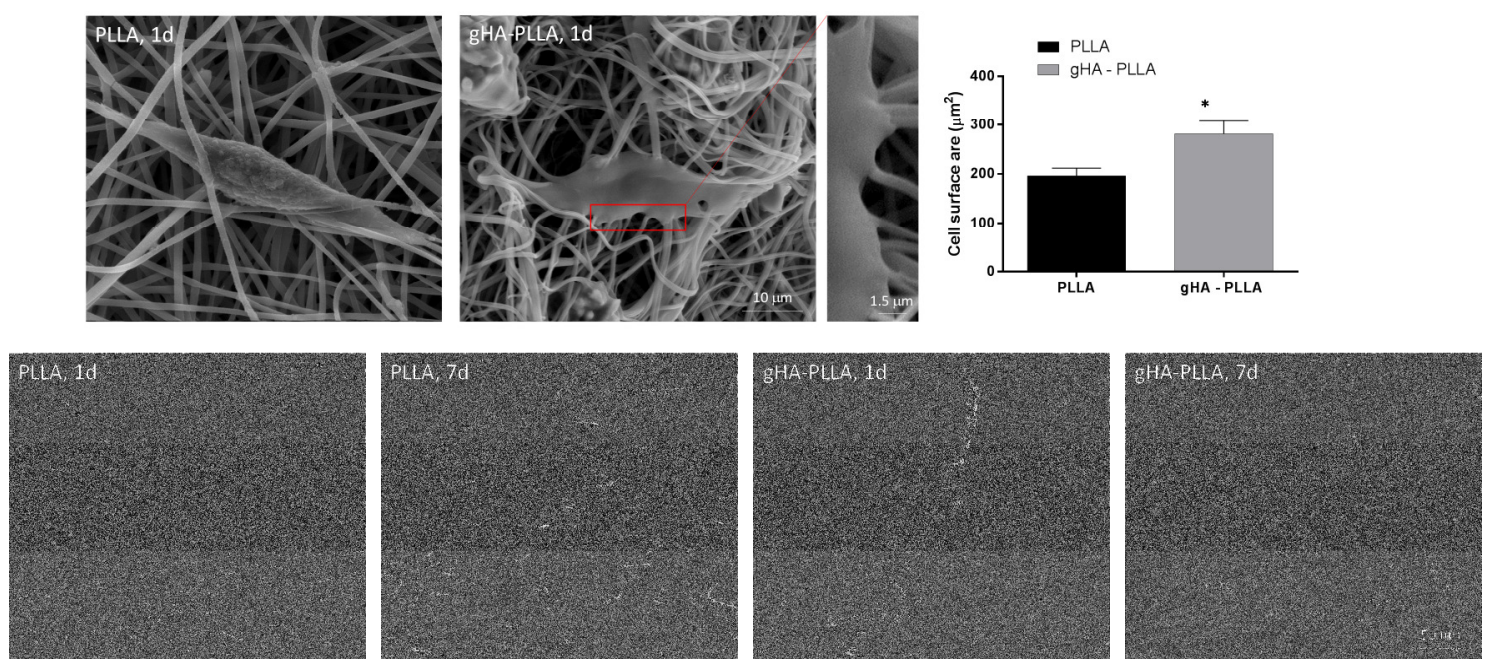

Figure 10. Morphology of MG-63 cells cultured on PLLA and gHA - PLLA, for 7 days. Graph shows the cell surface area determined at 1 day of culture. 


\section{Tables}

Table 1. Physical properties (fiber diameter, porosity and water contact angle) of PLLA and gHA-PLLA fiber membranes.

\begin{tabular}{l|lll}
\hline Sample & $\begin{array}{l}\text { Fiber average } \\
\text { diameter } \\
(\mathbf{n m})\end{array}$ & $\begin{array}{l}\text { Porosity } \\
(\boldsymbol{\%})\end{array}$ & $\begin{array}{l}\text { Water contact angle } \\
(\mathbf{(})\end{array}$ \\
\hline PLLA & $510 \pm 150$ & $79 \pm 3$ & $131 \pm 2$ \\
gHA-PLLA & $440 \pm 170$ & $88 \pm 5$ & $132 \pm 3$ \\
\hline
\end{tabular}

Table 2. The Ca:P ratio for pristine PLLA and gHA-PLLA immersed during 4 weeks in $1.5 \mathrm{xSBF}$.

\begin{tabular}{|c|c|c|}
\hline Sample & Time (weeks) & $\mathbf{C a} / \mathbf{P}$ \\
\hline \multirow{2}{*}{ PLLA } & 1 & $1.40 \pm 0.98$ \\
\hline & 4 & $1.35 \pm 0.59$ \\
\hline \multirow{2}{*}{ gHA-PLLA } & 1 & $0.95 \pm 0.06$ \\
\hline & 4 & $1.20 \pm 0.22$ \\
\hline
\end{tabular}

